Final version published as: Stephen, S., Elliott, R., \& Macleod, R. (2011). Person-centred therapy with a client experiencing social anxiety difficulties: a hermeneutic single case efficacy design. Counselling and Psychotherapy Research, 11, 55-66. DOI:

10.1080/14733145.2011.546203. CRoutledge. This is an author post-print and is not the version of record.

\title{
Person-centred therapy with a client experiencing social anxiety difficulties: a hermeneutic single case efficacy design
}

\author{
Susan Stephen', Robert Elliott and Rachel Macleod
}

Counselling Unit, University of Strathclyde, Glasgow, United Kingdom

\begin{abstract}
Background: Social anxiety is a chronic, debilitating psychological condition. Hermeneutic Single Case Efficacy Design (HSCED) is a legalistic mixed-method case study method for evaluating therapy efficacy in single cases. Aims: Using a case of Person-Centred Therapy (PCT) with a client experiencing social anxiety difficulties, we addressed the standard HSCED research questions of pre-post client change, causal role of therapy, and change processes. In addition, we explored adaptations to HSCED for ambiguous outcomes. Method: Based on a rich case record, affirmative and sceptic cases were constructed and adjudicated by three judges. Results: The judges held that the client changed considerably (but not substantially) and that therapy contributed considerably to client change. Change processes central to PCT were held to be active, as were client resources. Implications: The new procedures enabled judges to make sense of the ambiguous outcome data and can be further extended and developed. PCT can bring about considerable change in socially anxious clients.
\end{abstract}

Keywords: social anxiety; Hermeneutic Single Case Efficacy Design; person-centred therapy. 


\section{Person-centred therapy with a client experiencing social anxiety difficulties: a hermeneutic single case efficacy design}

\section{Introduction}

Drawing on the work of Kazdin (1981), Cook \& Campbell (1979), and, in particular, Bohart \& Boyd (1997), Elliott developed Hermeneutic Single Case Efficacy Design (HSCED; Elliott, 2001, 2002; Elliott, Partyka, Alperin et al, 2009), a case study research method for evaluating efficacy in counselling and psychotherapy. Together with Fishman's (1999) pragmatic case study approach and other quasi-judicial case methods (Bromley, 1986; Miller, 2004), HSCED forms part of a new case study movement in counselling and psychotherapy research. These approaches seek to develop systematic methods for overcoming the problems of previous case study methods, including reliance on anecdotal evidence, confirmatory bias, and "narrative smoothing" (McLeod, 2010).

In the HSCED method (Figure 1) multiple sources of quantitative and qualitative data are first organised into a rich case record that provides a range of evidence bearing on client change and the causal influence of therapy on outcome. This is the body of evidence on which subsequent analyses of the case is based. Opposing readings of the client's therapy are developed: one, the affirmative case, presents evidence that the client changed during the therapy, and that this change was brought about by the client's use of the therapy; the other, the sceptic case, is a good faith attempt to use the data to suggest plausible non-therapy explanations for any apparent change in the client. A recent further development (Elliott et al, 2009) is adjudication by a panel of judges who consider the arguments and supporting evidence and make decisions in relation to three central research questions: (1) Did the client change substantially over the course of therapy? (2) Is this change substantially due to the effect of the therapy? (3) What factors (including mediator or moderator variables) may be responsible for the change?

In this report we present an adjudicated HSCED study of a case in which a client experiencing social anxiety difficulties participated in twenty sessions of person-centred therapy (PCT). This form of therapy is based on the work of Carl Rogers $(1951,1957)$. Merry (2004) outlined the central principles of PCT as: the actualising tendency is understood to be the sole motivation for human behaviour, growth, change and development; the causal agent in promoting change is a therapeutic relationship in which the six necessary and sufficient conditions for psychological growth (Rogers, 1957) are present; and the therapist's nondirective attitude and behaviour communicates deep trust in the client's internal processes and capacity for personal change.

Social anxiety (or social phobia) difficulties typically include poor self-worth and a tendency to fear and avoid relationships and situations that involve social interactions. It has been estimated that the prior year prevalence of social anxiety disorder amongst people accessing outpatient psychological services is almost $20 \%$, compared with $4 \%$ in the general adult population (Stravynski, 2007). Social anxiety difficulties can have a chronic and debilitating impact on individuals' lives, sometimes leading to problems such as substance abuse and unemployment. A PCT view of social anxiety is that it is the result of conditions of worth placed on the person by significant others, the antidote for which is the therapist's genuinely compassionate, accepting and empathic attitude, which the client comes over the course of therapy to internalize. 
Until recently the few studies from which an inference might be drawn about the effectiveness of PCT for this client group were those in which some sort of "supportive therapy" was delivered as a control condition. The supportive therapies delivered in these studies typically take the form of non-bona fide versions of PCT administered by CBT researchers (Elliott \& Freire, 2008). For example, Cottraux et al (2000) compared CBT for social phobia with a supportive therapy described as a "therapy (that) used empathic listening, reformulation, clarification, recapitulation and showed positive consideration. Advice, exposure homework, psychoanalytical interpretations or cognitive modification techniques were prohibited" (p.138). This therapy was offered "as usual" for France as six 30-minute sessions on a fortnightly basis, while the comparison treatment, CBT, involved eight, weekly, hour-long individual sessions of cognitive therapy followed by six weekly 2 -hour group sessions of social skills training. The findings showed that the group receiving CBT scored better on most measures after 12 weeks of treatment.

Research in progress (Elliott \& Rodgers, 2010) is examining the effectiveness of two different bona fide forms of Person-Centred-Experiential therapy for people experiencing social anxiety, PCT and emotion-focused therapy (EFT). The authors of this report are researchers and therapists within this research, and this HSCED study focuses on the experience of one of its clients, seen in PCT. This is the second HSCED study arising from the research project; the first study (Macleod, Elliott \& Rodgers, in press) examined the therapy of a client who participated in the EFT arm of the project.

Early group outcome results from this study show that PCT can help clients who experience social anxiety difficulties, with very large pre-post effect sizes (Elliott \& Rodgers, 2010) for clients participating in the PCT arm of the project. However, this finding alone (a) does not tell us about the effectiveness of the therapy for individual participants nor (b) does it enable us to make strong causal inferences about the efficacy of PCT as a specific form of therapy, with these clients. In addition, (c) it does not develop our knowledge and understanding of what it is about PCT that can make a difference for a person who experiences social anxiety difficulties. These are the questions to which the HSCED study reported here begins to offer answers.

The case presented in this report was not selected for this study in order to illustrate a clearly successful example of PCT in action. Indeed, when we analysed the pre-post gain scores of our first group of participants, this client's gains were well below the mean for clients in the PCT arm. Instead this case was selected specifically because we envisaged a fourth important purpose for this study: to challenge the HSCED method by testing it with a case whose outcome appeared unclear.

The aims of this article are to outline the process of an HSCED investigation, illustrating how the method can be used to evaluate the outcome of a case in which the outcome of the therapy is not clear, and to provide some initial evidence about the effectiveness of PCT for a client experiencing social anxiety difficulties. The case materials developed for this HSCED investigation are available to readers as online appendices. These materials contain brief excerpts from the client's research interview but not a full transcript, in line with the consent given by the client for the presentation of her data in a scientific publication. The appendices can be accessed at [link: \{Note to editor: Please insert URL for on-line documents here\}].

\section{Method}




\section{Methodology}

Although randomised controlled trials (RCT) are currently viewed in the UK and around the world as the "gold standard" method for research into the efficacy of counselling and psychotherapy, many writers have highlighted limitations to the knowledge that can be gained from this methodology (Cook \& Campbell, 1979; Elliott, 2001; Freire, 2006; Haaga \& Stiles, 2000). A key problem is that in RCTs it is difficult to capture the complexity and subtlety of the therapy process, making it impossible to explain the causal relationship between client, therapy and any change that may have occurred.

Elliott (2001) argued that in many settings within society - for example, in legal and medical practice - skilled practitioners use systematic reasoning to develop and test inferences and make judgements about single events. This is an interpretive ("hermeneutic") process of trying to make sense out of complex and often-contradictory information. He introduced the HSCED method as "a set of practical procedures that are transparent, systematic, and self-reflective enough to provide an adequate basis for making inferences about therapy efficacy in single cases" (Elliott, 2001, p. 317). To this end, a rich mix of qualitative and quantitative data are sought, including information from both client and therapist and on process and outcome.

HSCED is also a critical-reflective method, involving good-faith attempts to work against one's preferences and expectations. To facilitate this process, legalistic methods such as a theory of evidence and argumentation, affirmative and sceptic sides, and external judges have been adopted (Elliott et al., 2009); these are used in order to bring out and clarify the key arguments. In short, HSCED is a systematic, interpretive, critical, legalistic, mixed methods research approach drawing on a wide range of psychotherapy and counselling research methods.

\section{Participants}

Client. The two main purposes of this study, to apply and to develop the HSCED method, dictated our criteria for selecting this case. First, we identified clients who had worked with PCT therapists while participating in the social anxiety project, and, second, we selected one client whose experience appeared, from initial examination, to offer evidence that might support the development of equally persuasive affirmative and sceptic arguments.

The selected client, named "Lucy" for the purposes of this study, was forty years old at the time of the therapy. A Scottish female, living alone, Lucy was employed in a professional role within a large public sector organisation. At the time therapy began she was about to take on a new, promoted position at work and was also moving home from the city to the countryside. At the screening interviews for the social anxiety project, her researcher used the Structured Clinical Interview for DSM-IV (SCID; First, Spitzer, Gibbon \& Williams, 2001) to confirm that Lucy's description of her longstanding difficulties met the DSM-IV criteria for social anxiety disorder and did not meet any of the exclusion criteria for the study (other current counselling or psychotherapy; current severe substance abuse, active psychosis, domestic violence, or more predominant difficulty, e.g., depression). During the screening process, Lucy also reported a history of childhood abuse and neglect and informed her researcher that she had participated in several types of therapy over a fifteen year period. Table 1 contains the list of that problems that Lucy identified. 
Before taking part in the social anxiety project, Lucy completed a consent form and a release of recordings form, in which she agreed that the data collected from her during the project could be used by members of the research team, for the recordings of her therapy sessions to be analysed for the purpose of developing and evaluating the form of therapy she was offered, and also for brief excerpts of the counselling sessions and research interviews to be presented at scientific meetings or in scientific publications in order to better understand what the therapeutic process is like for clients. She was given the opportunity to review both forms on each occasion that she met with her researcher: in the middle and at the end of therapy and also at each follow up interview.

Therapist. The therapist assigned to work with Lucy was trained as a psychologist and as a PCT psychotherapist, with twelve years' post-training experience at the time the therapy took place.

Lucy's Researcher. The researcher who worked with Lucy during her time at the research clinic was a Psychology graduate and had a diploma in counselling. Her therapeutic orientation was person-centred with an openness to more directive interventions such as EFT tasks. At the time of participating as a researcher in the study, she was a postgraduate student in Counselling Psychology. Upon meeting the client, she felt the case to be potentially very complex. She expected, at best, that the client might benefit from doing some work on her social anxiety processes.

HSCED Investigator. The HSCED investigator and first author of this paper is a BACP accredited counsellor, trained in PCT. She has a degree in law from a Scottish university and experience in preparing and presenting cases for adjudication. At the time she prepared the HSCED materials, she had not reached a conclusion about whether the client had changed substantially; this enabled her to approach the analysis with curiosity and to feel an affinity with each case as she developed it. She expected PCT to be effective for clients experiencing social anxiety difficulties but was unsure of the degree to which this may be evident for some clients within twenty sessions.

Research Supervisor/Auditor. The HSCED materials were audited by the first author's research supervisor before they were passed to the judges. The research supervisor is a professor of Counselling. He is the originator of the HSCED method and is trained in PCT and EFT. He expected PCT to be generally effective with social anxiety, but not for all clients.

Judges. The three judges were all experienced practitioners in counselling and psychotherapy and volunteered to take part in the project because of their interest in the use of case studies as a research method. Judge A had worked as a counsellor since 1999 and was trained in both PCT and EFT. She described herself as "broadly personcentred". Judge B was a clinical psychologist of many years' experience. She was trained in group analysis, family therapy, cognitive behavioural therapy and behavioural therapy. Judge $C$ was a person-centred counsellor and supervisor, who had been in practice since 2000. The HSCED investigator communicated with the three judges by email during the adjudication process. Each judge worked on their judgement independently. 


\section{Measures: assembling the rich case record}

Lucy completed a range of quantitative and qualitative instruments while participating in the study. These data were gathered together by the HSCED investigator and collated into a Rich Case Record (Appendix A).

Quantitative Outcome Measures. Five quantitative outcome measures were used to assess client change over therapy. These measures (with references to psychometric information) were: (1) Clinical Outcomes in Routine Evaluation - Outcome Measure (CORE-OM; Barkham et al, 2006), a general measure of clinical distress; (2) Strathclyde Inventory (SI; Freire, Elliott \& Cooper, 2007), a measure of congruenceincongruence; (3) Personal Questionaire (PQ; Wagner \& Elliott, 2004), a brief, individualized, weekly outcome measure, constructed and client and researcher before therapy; (4) Social Phobia Inventory (SPIN; Connor et al, 2000), a measure of social anxiety; (5) Inventory of Interpersonal Problems (IIP; Horowitz et al, 1988), a measure of interpersonal distress. Lucy completed each of these measures at pre-therapy (before session 1), mid-therapy (after session 8) and post-therapy (after session 20) and at follow up (six months following the end of therapy). Unfortunately, because of a data collection error, there was no pre-therapy data for the SI, CORE-OM and IIP.

Qualitative Assessment. A semi-structured interview (the Change Interview; Elliott, Slatick \& Urman, 2001) was the main opportunity to obtain Lucy's experiences of the changes and helpful and hindering processes in her therapy. These interviews between Lucy and her researcher occurred after the eighth session of therapy (mid-therapy interview) and at the end of therapy (post-therapy interview). She was also asked to rate her changes for: (1) how much they were expected or surprising to her; (2) how likely she thought they would have been without therapy; and (3) how important they were. She was also asked about events outside therapy that might have affected her process, and about medication. Because of the amount of data collected in each interview, only Lucy's post-therapy interview was examined in detail for this HSCED study, although some key data from her mid-therapy interview was included in the rich case record (Appendix A).

Lucy also completed a Helpful Aspects of Therapy (HAT) form at the end of each session, in which she was encouraged to write about aspects of the session that she experienced as particularly helpful or unhelpful (Llewelyn, 1988).

\section{HSCED analysis procedure}

Affirmative case. In HSCED, the purpose of the affirmative case is to persuade the judges that (1) the client changed substantially over the course of therapy, and (2) this change was substantially due to the therapy. The affirmative case carries the burden of proof and therefore presents its arguments first. Its presentation, like that of the sceptic case, is divided into three sequential segments: (a) a brief, setting out its main lines of argument; (b) a rebuttal, challenging the arguments in opposing sceptic brief; and (c) a concise summary narrative or closing argument. Elliott $(2001,2002)$ described five types of direct evidence linking therapy to client change (e.g., change in long-standing problems), for the affirmative case to draw upon in preparing its brief. He proposed that replication in the form of at least two types of evidence must be present. 
Sceptic case. The purpose of the sceptic case is to make a good-faith attempt to cast doubt on the idea that the client changed over the period of therapy and that any possible changes were the result of the therapy. To do this, the sceptic case systematically evaluates and supports alternative interpretations of the rich case record. The sceptic case consists of the same three segments as the affirmative case, brief, rebuttal and summary narrative, all aimed at challenging the affirmative case, thus enabling a balanced view of the evidence. Elliott $(2001,2002)$ identified eight alternative explanations that the sceptic case may consider in preparing its brief, four non-change explanations (e.g., statistical artefacts) and four non-therapy explanations (e.g., extra-therapy factors).

\section{Adjudication Procedure}

For this study, because it was anticipated that the decisions would not be clear-cut, the HSCED investigator revised the first adjudication question to separate out the extent to which the judges believed Lucy had changed, from the degree of certainty that they felt about this. This format was also followed in the second question, asking the judges to separate their evaluation of whether any change was due to the therapy from their confidence in this judgement. The judges were also asked to state what evidence presented in the affirmative and sceptic cases mattered most to them in reaching their conclusions on each question, and to describe how they made use of the evidence. Each judge received the rich case record, including a transcript of the post-therapy change interview, and the adjudication questions. The judges' instructions were to familiarise themselves with the data and arguments made by the affirmative and sceptic cases, then to answer the adjudication questions.

\section{Procedure to evaluate the validity of adjudication}

Following Elliott et al (2009), the data arising from the six month follow up interview data were withheld from the participants involved in the analysis and adjudication of the HSCED until after they had completed their parts in the study. Once the HSCED materials had been passed to the judges for adjudication, the HSCED investigator transcribed the follow up interview and collated the data in a follow-up case record (Appendix I). When the adjudication was complete, this record, including the transcript of the interview with Lucy, was given to the judges. They were invited to consider their decisions in light of this new information, and comment on their opinions, if appropriate.

\section{Results}

Rich case record

The following is a summary of Lucy's rich case record; the full record is provided at Appendix A.

Quantitative outcome data. Table 2 shows Lucy's pre-, mid- and post-therapy scores on the five outcome instruments: PQ, SPIN, CORE-OM, SI and IIP. (Some scores are missing pre-therapy; mid-therapy scores were used for these instead.) Table 1 provides details of the change on the individual items in Lucy's PQ. At post-therapy, Lucy's scores on all instruments remained above the clinical caseness cut-off. Her scores on the PQ and IIP demonstrated reliable positive change; on the SPIN and CORE-OM, no 
reliable change; and on the SI, reliable negative change. Lucy also completed her PQ at the beginning of every session. Figure 2 presents her mean scores across therapy and demonstrates that Lucy's PQ scores remained in the clinical range throughout her therapy, except at session 19.

Qualitative information about significant events. Lucy's Helpful Aspects of Therapy (HAT) forms provide a session-by-session record of events in therapy that Lucy found helpful or hindering. Lucy identified at least one helpful event in every session and no hindering events. She rated fifteen events as extremely or greatly helpful (Appendix A, Table A3). Many of Lucy's helpful events reported insights, such as following description from session 2:

Today there was a point on looking at the roots of my lack of sense of being a human. I realised this tied in with my awareness that my emotional development has been "underdeveloped". I had never equated the two before, and while other aspects come into play it has given me a new insight into the issue. (Rated "extremely helpful".)

Qualitative outcome assessment. In her change interview, Lucy was asked to identify any changes that she had noticed in herself over the course of therapy. Table 3 shows Lucy's changes at post-therapy: she was now more aware and accepting of her own difficulties, was seeing more people socially, had dropped some things that she had been forcing herself to do, had developed a lasting relationship during her time in therapy, had experienced a shift in her criteria of what she could accept within in a relationship, had opened up emotionally and felt she was able to be more vulnerable and less ashamed, was able to manage a relationship with a difficult colleague, and had been able to say no to this colleague despite her fear of the consequences. Lucy rated five changes as "surprising" or "somewhat surprising", and six as "unlikely" or "somewhat unlikely" to have happened without therapy. All seven changes felt "extremely" or "very important" to Lucy. Highlights from the post-therapy change interview are also included in the rich case record (Appendix A, Tables A6 to A13), and include helpful and hindering factors in four domains: (a) therapy, (b) her life situation, (c) personal characteristics, and (d) research.

\section{Affirmative brief}

The affirmative and sceptic briefs and rebuttals are summarised below; full versions can be found in the Appendices (summary narratives are Appendices F \& G).

The affirmative brief (Appendix B) argued that Lucy had changed over the course of therapy and that this change was the result of her participation in therapy. The main arguments put forward were that the changes Lucy described at post-therapy were substantial and relevant to her long-standing social anxiety difficulties; that Lucy attributed these changes to her therapeutic process; that the idiosyncratic descriptions she gave of her experience in therapy supported the credibility of her evidence; and that the link between the changes that Lucy experienced and her process was demonstrated in two ways: a comparison of Lucy's HAT forms and her post-therapy changes that indicated a connection between what happened in her therapy and its outcome, and three examples of significant events in Lucy's therapy that could be matched with reliable gains (of at least 1 point) in her weekly PQ scores. 


\section{Sceptic brief}

In response, the sceptic brief (Appendix C) presented alternative explanations that supported two main arguments: first, that Lucy's apparent changes were minor, and, second, that it was more likely that Lucy's own determination to change, and events in her life that had taken place during the time she was in therapy, accounted for those changes that did take place.

\section{Affirmative rebuttal}

The affirmative rebuttal (Appendix D) challenged those alternative explanations by arguing that, at the end of therapy, Lucy's distress about problems at work distorted her PQ score and probably also the scores on the other instruments. It also proposed that the inconsistencies in Lucy's evidence showed that it was genuine and that her hesitation could be understood in the context of her struggle with self-criticism and her tendency to "wait... for it all to fall apart" (Appendix D, Figure D1). There was also evidence that Lucy was still processing the significance of some of her experiences in therapy. Most important, it was argued that Lucy used her therapy to enhance her ability to be agent of her own change. This enabled her to achieve things that she had never believed would happen, demonstrated in her response to events in her life during that time.

\section{Sceptic rebuttal}

The sceptic rebuttal (Appendix E) argued that there was no evidence to infer that any changes Lucy had reported might be long-lasting, especially given the fluctuations in her PQ scores, and that the changes that Lucy described, although all "important", did not appear to have had a significant impact on her level of distress, her sense of self and her core problems.

\section{Adjudication}

Each judge worked on their judgment independently. Their individual conclusions are shown in Table 4 (see Appendix $\mathrm{H}$ for full set of opinions), along with mean and median scores on each question. We propose that the median score best represents a majority decision of the three judges; therefore, the overall decisions from the main adjudication were:

- That Lucy changed considerably over the course of therapy ( $80 \%$ certain)

- That this change was due to the therapy to a considerable extent (60\% certain)

Summary of opinions about change over course of therapy. Judge A reported giving the greatest weight to the quantitative data, which she felt did not support a claim that there had been a substantial change in Lucy's stable problems. She also found weaknesses in a number of the arguments put forward by the affirmative case. However, she concluded that a change in Lucy's difficulties might become more evident in the longer term. Judge B had a very different response to the arguments. She felt persuaded by the affirmative case, which she found to be closely argued and presenting clear evidence; she lost confidence in the sceptic case, in which she found contradictions. Of the three opinions on this question, it was Judge C who gave most weight to Lucy's own evidence, noting the importance of the specific changes Lucy had identified, as well as her ambivalence about the overall outcome of her therapy experience. Judge $\mathrm{C}$ modified her decision to "considerably" $(60 \%)$ in order to capture this. She said she had been persuaded by the affirmative case's argument that there was evidence that Lucy had 
developed her personal agency during therapy and that, given that this was short-term therapy, she felt that Lucy's achievements were remarkable.

Summary of opinions about whether change was due to therapy. Judge A accepted Lucy's evidence that the therapy had a significant role in bringing about the changes that she described in her interview and also the affirmative case's argument that Lucy had been supported to activate her own resources to help herself. Judge B also agreed with the arguments put forward by the affirmative case. Judge $\mathrm{C}$ accepted Lucy's evidence that the therapy had been a valuable tool and that she attributed to therapy the specific changes that she had described. This judge also noted that the changes experienced by Lucy could be attributed to the quality of the therapy that Lucy received.

Mediator Factors. Judge A identified two processes within the therapy that she felt had helped bring about change for Lucy: the discipline of talking about herself every week and focusing on the problems she was experiencing in her life; and the experience of being "heard and not destroyed" (Appendix H, p.56). Judge B noted the therapist's "minimal profile" and commented that this would require a great sensitivity and responsiveness to Lucy's needs. She observed that this allowed Lucy to talk and, through talking while feeling safe, develop insight. Judge C proposed the therapist's use of metaphor appeared to have been helpful within Lucy's therapy.

Moderator Factors. Finally, the judges were asked to identify the characteristics or personal resources that helped Lucy to make use of her therapy. Judge A noted that Lucy was an experienced user of therapy, so knew what to expect, and was also highly motivated to work on her problems. Judge B felt that Lucy's intelligence and education were important factors. Judge C identified Lucy's willingness to engage in the therapeutic process, her sense of humour, and her ability to reflect on her process, experience new insights and build on the understanding she had gained from previous therapy.

\section{Review of adjudication}

For the first time in an HSCED study, the judges were invited to see the data that Lucy provided at her six month follow up interview (see Appendix I). They were asked whether they felt their original decisions should be adjusted in light of the new information. Only Judge $C$ wished to revise her decision, reducing her answer to Question 1 from Considerably (60\%) to Moderately (40\%).

\section{Discussion}

The judges in this case decided that Lucy had changed considerably over the course of therapy and that this change was considerably due to the effects of her therapy.

Although neither decision meets the standard of substantial change proposed by Elliott (2002), this result shows that the HSCED method offers the potential to capture the complexities of a case in which the outcome is not clear-cut.

The judges identified the mediating factors, or causal processes within the therapy that each believed had been most helpful to Lucy. The disciplined weekly practice of talking about herself and focusing on her problems; being "heard and not destroyed" (the client's experience of her therapist's empathy and acceptance); the therapist's non-directivity or "minimal profile" (in Judge B's words), her sensitivity and 
responsiveness to Lucy's needs, allowing Lucy to talk while feeling safe and thus to develop insight (the therapist's non-directivity) and the therapist's use of metaphor (her idiosyncratic empathic response to the client) were identified as the causal processes for Lucy's change. Each of these factors is consistent with the theory of person-centred therapy. In addition, Lucy's previous experience of therapy, her motivation, and her willingness and ability to engage in the therapeutic process were each identified as moderator variables in Lucy's change. These factors are consistent with Orlinsky, Rønnestad, \& Willutzki's (2004) conclusion that the key predictors of positive outcome in therapy are the client's level of active participation, willingness to work collaboratively and cooperatively with their therapist, and openness to the process.

On the basis of these conclusions, it seems plausible to suggest that, had Lucy continued in this therapy beyond the twenty sessions offered within the research project, she might have experienced further and more substantial change. Thus, because of the limits of the research protocol, it seems likely that the potential of her therapeutic process was not fully realised. This raises the question of whether twenty sessions of PCT is sufficient, at least for some clients.

The judges' ruling that Lucy had changed considerably over the course of therapy represented a majority rather than a unanimous decision. It was in this question that the greatest difference in opinion was evident, with Judges A and B, in particular, having very different reactions to the arguments put forward by the affirmative and sceptic cases. Nevertheless, the judges expressed a high degree of certainty about their individual decisions (median $=80 \%$ ). We had expected the judges to experience greater difficulty in making their decision. Their comments did not suggest that this had been the case; rather they appear to have been persuaded by the arguments and cohesiveness of one or other case. Given that one or more judge was convinced by each case, it does not appear that the presentation of either case was biased. It is more likely that the arguments put forward by the preferred case fit with that judge's own personal views.

Nevertheless, the question of the definition of substantial change remains. The hypothesis underlying the HSCED method of adjudication is that if three judges recognise substantial change using their own understanding of therapeutic process then the standard of proof has been met. But what if these judges have very different ideas of what substantial change means or if their views alter when presented with the evidence? Gordon, Grummon, Rogers et al (1954: 28-29) commented that "such a criterion as 'success' in therapy must have a solid, known meaning acceptable to all." It is clear that different forms of therapy have different aims and therefore different indicators of success. Should the HSCED judges evaluate change in a particular therapy using that individual therapy's own definition of change? If so, would that make it difficult to compare HSCED results across therapies? Alternatively, should HSCED judges work with an agreed definition of substantial change that would apply to all therapies? Whether a definition of substantial change, as applied within the HSCED, should be clarified requires further consideration.

The judges were closer in their opinions on the extent to which Lucy's change was due to the therapy, but not in the ratings they gave, with each judge choosing a different anchor on the scale. This suggests that the judges may have had different understandings of the anchors used in the scale or how their decision might rate on the scale. It seems likely that further development of the rating scale is necessary in order to reduce the scope for different interpretations of the anchors used. Nevertheless, it appears that a key argument of the affirmative case - that therapy enabled Lucy to be 
agent of her change - fit with the judges' perceptions of her therapeutic process. This suggests that the HSCED process can demonstrate the interaction between the client's use of therapy and how they process this in their life outside the therapy room: the concept of cross-contextual practice (Mackrill, 2007). There is scope to further develop the HSCED method by asking the judges for their opinions on how the client used the opportunities within and outside therapy to achieve change.

This study offered the chance to test potential developments in the HSCED method because of the challenge posed by the complexities of Lucy's experience. These developments were twofold: first, within the analysis process, new methods were used to deepen the evidence presented in the affirmative case; second, in the adjudication process, the attempt to offer a more open rating scale with the potential of capturing a more complex result.

On the basis of this study, we propose the following developments to further improve the adjudication process: (1) more preparation for judges, including the development of guidance concerning how certain forms of evidence might be used; (2) further improvement of the rating scales; and (3) judges working together on the adjudication to reach a consensus. (4) A further recommendation is to ask the judges for their opinions on those factors that might have inhibited change. Evidence existed in the rich case record and analyses that would have enabled the judges to give opinions on this question. In a complex case such as the one studied here, this information might have been important for developing a full understanding of what happened and for improving the therapy. (5) Great care was taken in the preparation of this case to consider its impact on the client. However it is also important that the impact on the therapist be considered. In future HSCEDs, we recommend that the rich case record include a statement from the therapist outlining his or her view of the outcome of the therapy.

This case study establishes the possibility that PCT can be helpful for clients with social anxiety and self-esteem issues, and has identified the processes within the therapy that the client in this case found most beneficial. Further HSCEDs evaluating PCT for clients experiencing social anxiety difficulties must be carried out before it will be possible to assess the extent to which the outcome of this case represents a typical experience of PCT for a client in Lucy's circumstances and characteristics, that is, (a) long-standing social anxiety, (b) history of childhood abuse and neglect, (c) experienced as a user of therapy, (d) high motivation to engage in the therapeutic process, and (e) current and continuing significant life stressors.

\section{Conclusions and recommendations for further research}

A person experiencing social anxiety difficulties can achieve considerable change through participating in twenty sessions of PCT, with change being attributable to key aspects of PCT and the client's own resources. For some clients, however, twenty sessions may not be enough to fully realise the potential of the therapy.

Judges in an HSCED study may reach different conclusions about how much the client changed while still agreeing that the change experienced by the client was due, to a considerable extent, to the way that she used her therapy. The HSCED method shows potential as a systematic self-reflective process that can integrate multiple variables and viewpoints even with complex, mixed outcomes. However, additional research can further develop the method. 
This was a complex case and may not be representative of other clients' experience of PCT. Replication of this study is required. More HSCEDs evaluating the efficacy of PCT for clients experiencing social anxiety difficulties need to be carried out so that a body of "case law" can be developed. This will enable the creation of generalised knowledge containing strong inferences about the specific causal processes and facilitative conditions that contribute to the efficacy of PCT for people experiencing social anxiety difficulties.

\section{Acknowledgements}

We would like to thank the client and therapist, and the three judges, Marijke Moerman, Anja Rutten and Margaret Whitelaw, for their participation in this study.

\section{References}

Barkham, M., Mellor-Clark, J., Connell, J., \& Cahill, J. (2006). A core approach to practice-based evidence: A brief history of the origins and applications of the CORE-OM and CORE System. Counselling and Psychotherapy Research, 6:1, 3-15.

Bohart, A.C., \& Boyd, G. (1997). Clients' construction of the therapy process: a qualitative analysis. Poster presented at the meeting of the North American Chapter of the Society for Psychotherapy Research.

Bromley, D.B. (1986). The Case-study Method in Psychology and Related Disciplines. Chichester: John Wiley \& Sons Ltd.

Connor, K., Davidson, J., Churchill, L., Sherwood, A., Foa, E. \& Weisler, R., (2000). Psychometric properties of the social phobia inventory. British Journal of Psychiatry, 176, 379-386.

Cook, T.D., \& Campbell, D.T. (1979). Quasi-experimentation: Design and analysis issues for field settings. Chicago: Rand McNally.

Cottraux, J., Note, I., Albuisson, E., Yao, S.N., Note, B., Mollard, E., Bonasse, F., Jalenques, I. Guérin, J, \& Coudert, A.J. (2000). Cognitive Behaviour Therapy versus Supportive Therapy in Social Phobia: A Randomized Controlled Trial. Psychotherapy and Psychosomatics 69, 137-146.

Elliott, R. (2001). Hermeneutic single case efficacy design (HSCED): An overview. In K.J. Schneider, J.F.T. Bugental \& J.F. Fraser (eds.), Handbook of Humanistic Psychology (pp.315-324), Thousand Oaks, CA: Sage.

Elliott, R. (2002). Hermeneutic Single Case Efficacy Design. Psychotherapy Research $12,1-21$.

Elliott, R. \& Freire, E.S. (2008). Person-Centred \& Experiential Therapies are Highly Effective: Summary of the 2008 Meta-analysis. Person-Centred Quarterly, November 2008.

Elliott, R., Partyka, R., Alperin, R., Dobrenski, R., Wagner, J., Messer, S.B., Watson, J.C., \& Castonguay, L.J. (2009). An adjudicated hermeneutic single-case efficacy design study of experiential therapy for panic/phobia. Psychotherapy Research 19, 543-557.

Elliott, R. \& Rodgers, B., (2010). Person-Centred/Experiential Approaches to Social Anxiety: Initial Outcome Results. Paper presented at the UK-SPR conference, Ravenscar, UK.

Elliott, R., Slatick, E., \& Urman, M. (2001). Qualitative change process research on psychotherapy: Alternative strategies. In J. Frommer \& D.L. Rennie (Eds.), 
Qualitative Psychotherapy Research: Methods and Methodology. Lengerich, Germany: Pabst Science Publishers.

First, M. B., Spitzer, R.L., Gibbon, M., \& Williams, J.B.W. (2001). Structured Clinical Interview for DSM-IV-TR Axis I Disorders, Research Version, Patient Edition With Psychotic Screen. New York: Biometrics Research, New York State Psychiatric Institute.

Fishman, D.B. (1999). The case for pragmatic psychology. New York: NYU Press.

Freire, E.S. (2006). Randomized controlled clinical trial in psychotherapy research: An epistemological controversy. Journal of Humanistic Psychology, 46, 323-335.

Freire, E.S., Elliott, R., \& Cooper, M. (2007). The Strathclyde Inventory: Validation of a person-centred outcome measure. Paper presented at the $13^{\text {th }}$ Annual BACP research conference, York, UK.

Gordon, T., Grummon, D.L., Rogers, C.R., \& Seeman, J. (1954) Developing a Program of Research in Psychotherapy. In C.R. Rogers \& R.F. Dymond (eds.) Psychotherapy and Personality Change (pp. 12-34). Chicago: The University of Chicago Press.

Haaga, D.A.F. \& Stiles, W.B. (2000). Randomized clinical trials in psychotherapy research: Methodology, design, and evaluation. In C.R. Snyder \& R.E. Ingram (eds.), Handbook of psychological change (pp. 14-39). New York: John Wiley.

Horowitz, L.M., Rosenberg, S.E., Baer, B.A., Ureno, G. \& Villasenor, V.S. (1988). Inventory of interpersonal problems: psychometric properties and clinical applications. Journal of Consulting and Clinical Psychology, 56, 885-892.

Kazdin, A.E. (1981). Drawing valid inferences from case studies. Journal of Consulting and Clinical Psychology, 49, 183-192.

Llewelyn, S. (1988). Psychological Therapy as viewed by Clients and Therapists. British Journal of Clinical Psychology 27, 223-238.

Macleod, R., Elliott, E., \& Rodgers, B. (in press). Process-Experiential/Emotionfocused Therapy for Social Anxiety: A Hermeneutic Single-Case Efficacy Design Study. Psychotherapy Research.

Mackrill, T. (2007). Using a cross-contextual qualitative diary design to explore client experiences of psychotherapy. Counselling \& Psychotherapy Research, 7(4), 233-239.

McLeod, J. (2010). Case Study Research in Counselling and Psychotherapy. London: Sage.

Merry, T. (2004). Classical client-centred therapy. In P. Sander (ed), The Tribes of the Person-Centred Nation: A guide to the schools of therapy related to the PersonCentred Approach (pp. 21-44). Ross-on-Wye: PCCS Books Ltd.

Miller, R.B. (2004). Facing Human Suffering: Psychology and Psychotherapy as Moral Engagement. Washington D.C.: American Psychological Association.

Orlinsky, D.E., Rønnestad, M.H. \& Willutzki, U. (2004). Fifty years of psychotherapy process-outcome research: continuity and change. In M.J. Lambert (ed.) Bergin and Garfield's Handbook of Psychotherapy and Behavior Change (pp.307-390). Chicago: John Wiley \& Sons.

Rogers, C.R. (1951). Client-centered therapy. Boston, MA: Houghton Mifflin.

Rogers, C.R. (1957). The necessary and sufficient conditions of therapeutic personality change. Journal of Consulting Psychology, 21, 95-103.

Stravynski, A. (2007). Fearing Others: The nature and treatment of social phobia. Cambridge, UK: Cambridge University Press. 
Wagner, J. \& Elliott, R. (2004). The simplified personal questionnaire. Unpublished manuscript, University of Toledo.

\section{Biographies}

Susan Stephen (formerly Cornforth) is a person-centred counsellor and supervisor working in private practice in Ayrshire. She conducted this HSCED study for her MSc in Counselling at the University of Strathclyde where, since 2008, she has participated as a therapist and researcher in the Social Anxiety research project.

Robert Elliott is Professor of Counselling in the Counselling Unit at the University of Strathclyde, Glasgow, Scotland. He is co-author of Facilitating Emotional Change and Learning Emotion-Focused Therapy. He is recipient of the distinguished career award of the Society for Psychotherapy Research and of the 2008 Carl Rogers Award of the Division of Humanistic Psychology of the American Psychological Association.

Rachel Macleod is a Counselling Psychologist working in secondary care in the NHS. She has been involved as a researcher in the Strathclyde Psychotherapy Project since 2007, and has taken part in a number of HSCED studies, in the roles of author, researcher and judge. 
Table 1. Lucy's Personal Questionnaire items, ratings and duration

\begin{tabular}{lllll}
\hline Item & $\begin{array}{l}\text { Duration of } \\
\text { Problem }\end{array}$ & Pre & Mid - 8 & Post \\
\hline $\begin{array}{l}\text { I have low self esteem and a negative } \\
\text { perception of my self-worth. }\end{array}$ & $>10$ years & 6 & 4.5 & 4 \\
I feel anxious around people. & $>10$ years & 6 & 4.5 & 4 \\
I lack assertiveness. & $>10$ years & 6 & 5 & 4 \\
I feel unable to challenge other people. & $>10$ years & 5 & 5 & 4 \\
I feel unable to manage change & $>10$ years & 5 & 4.5 & 3.5 \\
effectively. & & & & \\
I feel unable to handle conflict. & $>10$ years & 5 & 4.5 & 4 \\
I feel depressed about my situation. & $>10$ years & 4 & 4 & 5 \\
\hline
\end{tabular}

Notes. Maximum possible (7), very considerably (6), considerably (5), moderately (4), little (3), very little (2), not at all (1). 
Table 2. Lucy's Outcome Data

\begin{tabular}{lccccc}
\hline Instruments & Cut-off & RCI Min & Pre & Mid-8 & Post \\
\hline Personal Questionnaire & $<3.5$ & $1.0(\downarrow)$ & $\mathbf{5 . 2 9}$ & $\mathbf{4 . 5 7}$ & $\mathbf{4 . 0 7 * ( + )}$ \\
Social Phobia Inventory & $<1.12$ & $0.67(\downarrow)$ & $\mathbf{3 . 1 2}$ & $\mathbf{2 . 3 5 *}(+)$ & $\mathbf{2 . 5 9 ( = )}$ \\
CORE-OM & $<1.25$ & $0.5(\downarrow)$ & - & $\mathbf{1 . 9 7}$ & $\mathbf{2 . 2 6 ( = )}$ \\
Strathclyde Inventory & $>1.69$ & $.46(\uparrow)$ & - & 2.35 & $\mathbf{1 . 6 1 * ( - )}$ \\
$\begin{array}{l}\text { Inventory of Interpersonal } \\
\text { Problems }\end{array}$ & $<1.5$ & $0.57(\downarrow)$ & - & $\mathbf{2 . 9 4}$ & $\mathbf{2 . 3 1 * ( + )}$ \\
\hline$*$ p $<.2 ; * *$ p $<.05$ & & & & &
\end{tabular}

Note. Value in bold fall within the clinical range; $\uparrow=$ increased score indicates positive change; $\downarrow=$ decreased score indicates positive change; $(+)=$ reliable positive change in relation to first available score; $(=)=$ no change in relation to first available score; $(-)=$ reliable negative change in relation to first available score. 
Table 3. Lucy's changes reported at post-therapy

\begin{tabular}{|c|c|c|c|}
\hline Change & $\begin{array}{l}\text { How } \\
\text { expected/surprising } \\
\text { change was }\end{array}$ & $\begin{array}{l}\text { How unlikely/likely } \\
\text { change would have } \\
\text { happened without } \\
\text { therapy }\end{array}$ & $\begin{array}{l}\text { Importance of } \\
\text { change }\end{array}$ \\
\hline $\begin{array}{l}\text { More aware and accepting of } \\
\text { own difficulties }\end{array}$ & $\begin{array}{l}\text { Somewhat } \\
\text { expected }\end{array}$ & Somewhat unlikely & Very \\
\hline Seeing more people socially & $\begin{array}{l}\text { Somewhat } \\
\text { surprising }\end{array}$ & Neither & Very \\
\hline $\begin{array}{l}\text { Dropping some things that had } \\
\text { been forcing self to do }\end{array}$ & $\begin{array}{l}\text { Somewhat } \\
\text { surprising }\end{array}$ & Somewhat unlikely & Extremely \\
\hline $\begin{array}{l}\text { Lasting new relationship and } \\
\text { shift in criteria relating to what } \\
\text { might be ok in a relationship }\end{array}$ & Surprising & Unlikely & Extremely \\
\hline $\begin{array}{l}\text { Opened up emotionally, able } \\
\text { to be more vulnerable and less } \\
\text { ashamed }\end{array}$ & Surprising & Unlikely & Extremely \\
\hline $\begin{array}{l}\text { Able to manage relationship } \\
\text { with difficult colleague }\end{array}$ & $\begin{array}{l}\text { Somewhat } \\
\text { expected }\end{array}$ & Unlikely & Extremely \\
\hline $\begin{array}{l}\text { Able to say no despite fear of } \\
\text { the consequences }\end{array}$ & Surprising & Unlikely & Extremely \\
\hline
\end{tabular}


Table 4. Adjudication Decisions

\begin{tabular}{|c|c|c|c|c|c|}
\hline & $\begin{array}{l}\text { Judge } \\
\text { A }\end{array}$ & Judge B & Judge C & Mean & Median \\
\hline $\begin{array}{l}\text { 1a. To what extent did Lucy } \\
\text { change over the course of } \\
\text { therapy? }\end{array}$ & $20 \%$ & $60 \%$ & $60 \%$ & $47 \%$ & $60 \%$ \\
\hline 1b. How certain are you? & $80 \%$ & $60 \%$ & $80 \%$ & $73 \%$ & $80 \%$ \\
\hline $\begin{array}{l}2 \mathrm{a} \text {. To what extent is this due } \\
\text { to the therapy? }\end{array}$ & $40 \%$ & $60 \%$ & $80 \%$ & $60 \%$ & $60 \%$ \\
\hline 2b. How certain are you? & $60 \%$ & $60 \%$ & $80 \%$ & $67 \%$ & $60 \%$ \\
\hline
\end{tabular}

Notes. Anchors for questions $1 \mathrm{a}$ and $2 \mathrm{a}$ : no change (0\%), slightly $(20 \%)$, moderately $(40 \%)$, considerably $(60 \%)$, substantially $(80 \%)$, completely $(100 \%)$. 


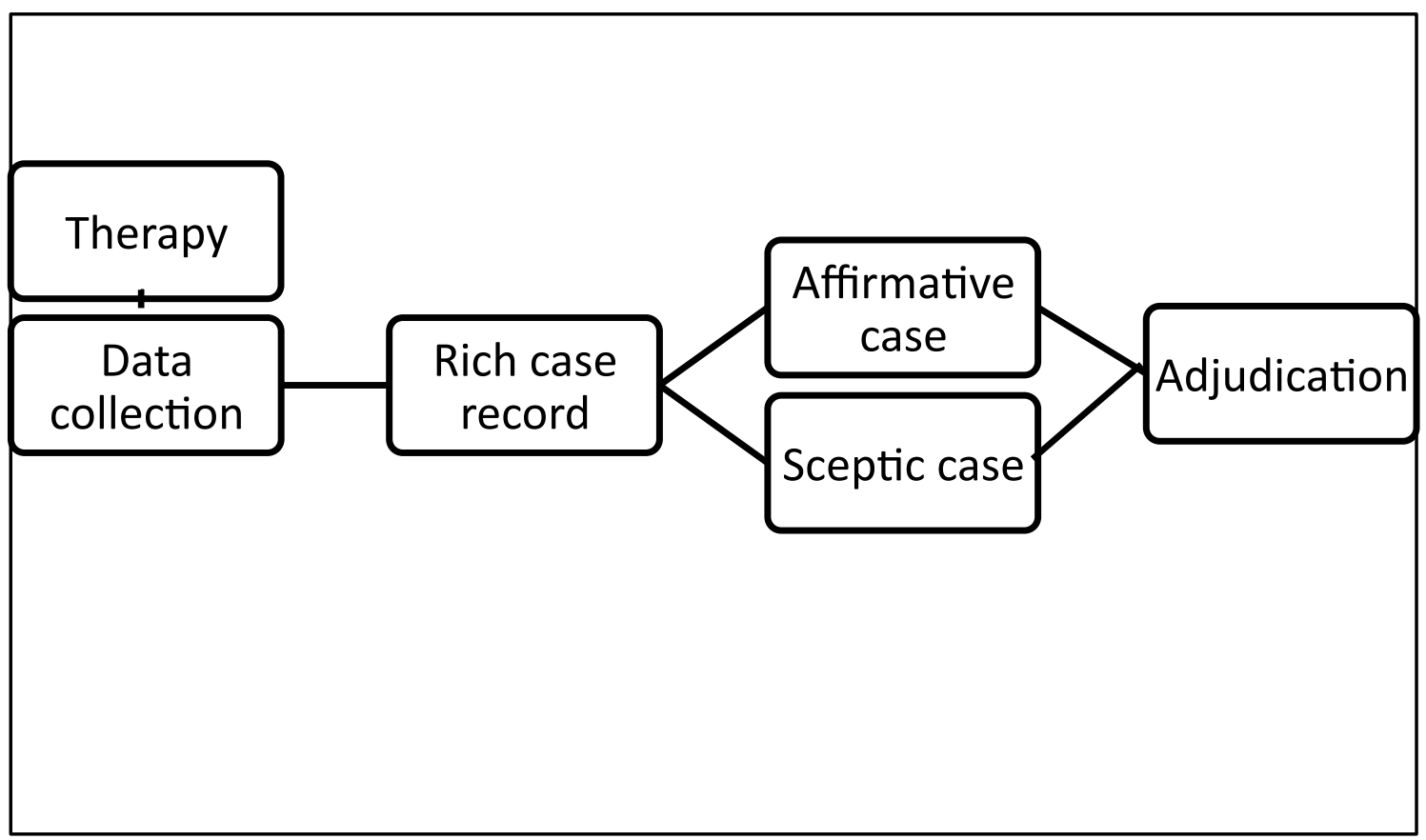


Figure 2. Lucy's mean PQ score across therapy

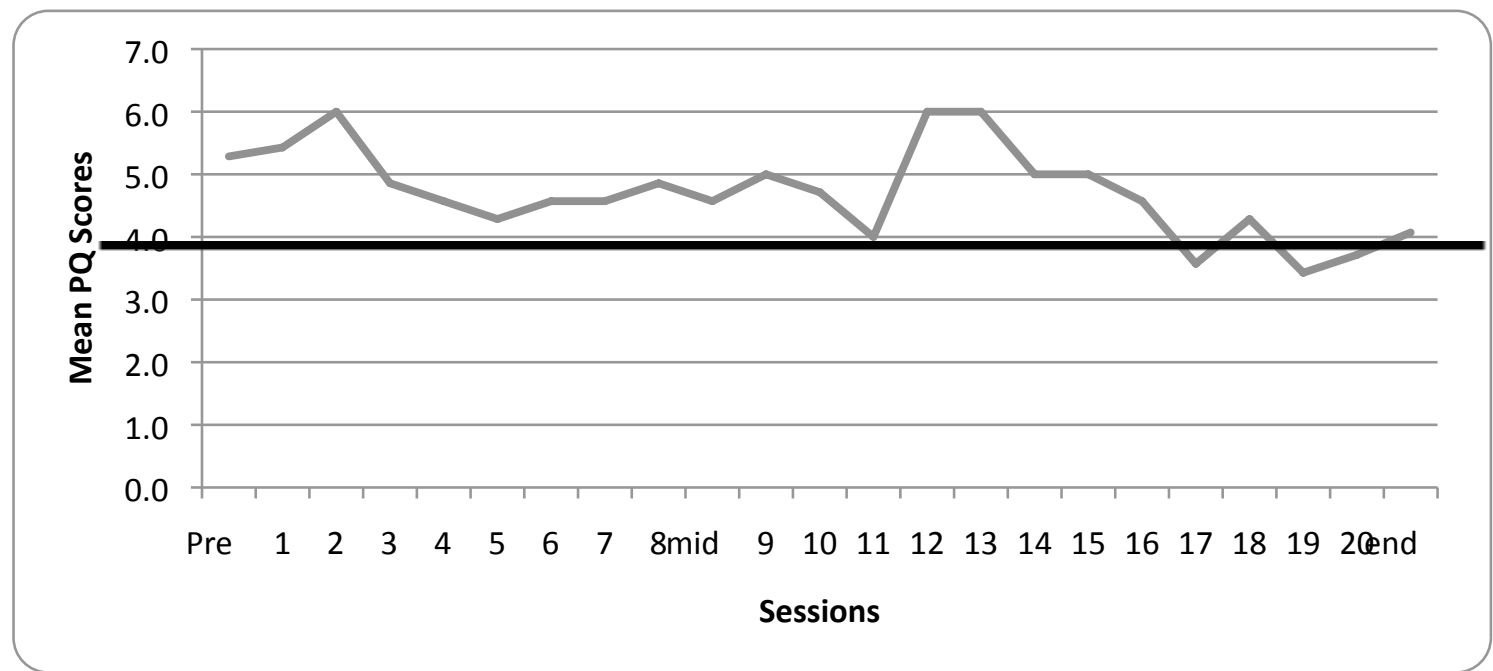

Note. The dark line indicates the cut-off point between the clinical and non-clinical range on this measure (3.5). 